biological control are due rather to good luck than to careful planning. Nevertheless it is amply clear that the successes obtained justify the expenditure involved and we may hope that when we understand the natural control of insect and plant pests more fully we can improve on our present methods.

W. R. Thompson.

\title{
Kenneth Bowman
}

The death of Kenneth Bowman at Edmonton on September 25, 1955 deprived Alberta of one of its most energetic collectors of Lepidoptera. Born at Durham, England in 1875 he early showed signs of developing into a keen student of natural history in all of its phases but his particular interest always centred around building comprehensive collections of the Lepidoptera of the districts in which he lived. Thus, when he came to Blackfalds in Alberta in 1904 and moved on to Edmonton in 1905, he quickly adapted his knowledge of the Macrolepidoptera of England to local conditions. His profession, as chartered accountant, took him frequently into three mountain passes which gave him an opportunity to collect extensively both on the plains and in the mountains of Alberta. By 1919 he had published a list of over 900 Macrolepidoptera taken in this province.

He now turned his attention increasingly to collecting the almost completely neglected Microlepidoptera of this part of Canada. He was blessed with the ability and the persistence to prepare well-nigh perfect specimens of these moths, many of which are exasperatingly minute and delicate.

Though he was fortunate, in his early years of collecting in this group, in obtaining taxonomic assistance in cercain families from Dr. J. H. MacDunnough in Ottawa, he was seriously handicapped in later years by being unable to find any specialists on this continent who were willing or able to classify the bulk of his steadily increasing Microlepidoptera. He possessed an unusually well-developed "eye for species" which enabled him to build up many series of what were undoubtedly representatives of true species.

By 1951, however, he had so succeeded in his quest for determiners that he was in a position to publish a completely revised list containing over 1,800 names of the Lepidoptera of Alberta, of which the magnificent total of 653 referred to Microlepidoptera. Despite the advance he thus made towards a more complete knowledge of the Microlepidoptera of Alberta his collection contained somewhat over 100 species which, at the time of his death, no one had attempted to name. A reason, given by one specialist, is that many of these are undoubtedly "new to science".

Most appropriately, his entire collection has now been acquired by the University of Alberta where, with the equally valuable collection of Coleoptera made by the late Mr. F. S. Carr, it will take its place as a permanent memorial to the industry of two of Alberta's pioneer amateur Entomologists.

This, in part, is the lasting contribution made by Kenneth Bowman to a knowledge of the Lepidoptera of Canada. He recognized as "new" many of the Macrolepidoptera which he collected. Though he described a few of these himself, his more normal procedure was to give specialists the privilege of so doing.

Members of the recently established Entomological Society of Alberta, of which he was a charter member, mourn with Mrs. Bowman and her daughter the passing of a loved associate and friend but are grateful for the permanent benefit they have gained from his life-long devotion to his valuable hobby. 